\title{
Article
}

\section{Study of the Bond Capacity of FRCM- and SRG-Masonry Joints}

\author{
Karrar Al-Lami ${ }^{1,2}$, Tommaso D'Antino ${ }^{1}\left(\mathbb{D}\right.$ and Pierluigi Colombi ${ }^{1, *}$ \\ 1 ABC Department of Architecture, Built Environment and Construction Engineering, Politecnico di Milano, \\ 20133 Milan, Italy; karrar.allami@polimi.it (K.A.-L.); tommaso.dantino@polimi.it (T.D.) \\ 2 Civil Engineering Department, College of Engineering, University of Wasit, Al-Rabee st, Wasit 00964, Iraq \\ * Correspondence: pierluigi.colombi@polimi.it; Tel.: +39-02-2399-4280
}

check for

updates

Citation: Al-Lami, K.; D'Antino, T.; Colombi, P. Study of the Bond Capacity of FRCM- and SRG-Masonry Joints. CivilEng 2021, 2, 68-86. https://doi.org/10.3390/civileng2010005

Received: 13 December 2020 Accepted: 6 January 2021

Published: 10 January 2021

Publisher's Note: MDPI stays neutral with regard to jurisdictional clai$\mathrm{ms}$ in published maps and institutional affiliations.

Copyright: $\odot 2021$ by the authors. Licensee MDPI, Basel, Switzerland. This article is an open access article distributed under the terms and conditions of the Creative Commons Attribution (CC BY) license (https:// creativecommons.org/licenses/by/ $4.0 /)$.

\begin{abstract}
Fiber-reinforced cementitious matrix (FRCM) and steel-reinforced grout (SRG) have been increasingly applied as externally bonded reinforcement to masonry members in the last few years. Unlike fiber-reinforced polymer (FRP), FRCM and SRG have good performance when exposed to (relatively) high temperature and good compatibility with inorganic substrates, and they can be applied to wet surfaces and at (reasonably) low temperatures. Although numerous studies investigated the mechanical properties and bond performance of various FRCM and SRG, new composites have been developed recently, and their performance still needs to be assessed. In this study, the bond behavior of three FRCM composites and one SRG composite applied to a masonry substrate is investigated. Sixteen single-lap direct shear tests (four tests for each composite) are performed. The FRCM studied comprised one layer of carbon, PBO (polyparaphenylene benzobisoxazole), or alkali-resistant (AR)-glass bidirectional textile embedded within two cement-based matrices. The SRG composite comprised one layer of a unidirectional stainless-steel cord textile embedded within a lime-based matrix. The results show a peculiar bond behavior and failure mode for each composite. Based on these results, the behavior of the carbon and PBO FRCM is modeled solving the bond differential equation with a trilinear cohesive material law (CML).
\end{abstract}

Keywords: FRCM; SRG; masonry substrate; shear test; analytical approach

\section{Introduction}

The strengthening and retrofitting of existing concrete and masonry structures have attracted great attention in the last few decades. Fiber-reinforced polymer (FRP) composites have been largely used as an externally bonded reinforcement (EBR) of existing structural and non-structural concrete and masonry members due to their high mechanical properties, durability, and ease of installation [1-4]. Nonetheless, FRP EBR has some disadvantages mainly associated with the use of organic matrices (usually epoxy resins), which have poor performance at (relatively) high temperature (close to or higher than their glass transition temperature), produce toxic fumes if heated, cannot be applied to wet surfaces, and have poor physical-chemical compatibility with inorganic substrates. In order to accommodate these drawbacks, the organic matrix was replaced with inorganic matrices, such as cement, hydraulic lime, and geopolymer mortars [5-7]. However, the impregnation of continuous fiber sheets was difficult in this case due to the size of micro-aggregates in the matrix. Therefore, to improve the matrix-fiber bond behavior and allow the stress transfer between different layers of matrix, fiber sheets were replaced with open-mesh textiles [8]. This type of composite is usually referred to as fiber-reinforced cementitious matrix (FRCM), textilereinforced mortar (TRM) [8-11], or, when the textile comprises steel cords, steel-reinforced grout (SRG) $[6,12,13]$.

Textiles made of different high-strength fibers can be used in FRCM composites, such as aramid, basalt [14,15], carbon [7,16], PBO (polyparaphenylene benzobisoxazole) [17,18], and alkali-resistant (AR) glass $[19,20]$. Textiles are generally organized in a bidirectional open mesh configuration. The textile configuration (size, directions, and shape of single 
yarn, spacing between yarns) can be modified to provide specific properties to the composite $[21,22]$. Furthermore, textile yarns can be coated with resin to protect them, facilitate their handling and installation, and improve the matrix-fiber bond behavior. In SRG composites, galvanized or stainless-steel cords are employed. These cords are organized in unidirectional textiles and can have different spacing depending on the performance sought $[6,8,23]$.

FRCM and SRG have progressively become attractive for strengthening and retrofitting both masonry and concrete structures for their competitive cost, resistance to (relatively) high temperatures, compatibility with the substrate, and applicability on wet surfaces and at (reasonably) low temperatures. The main difference between FRCM for concrete or masonry applications lies in the matrix employed, which should be ad hoc engineered to optimize the compatibility with the substrate [21,22]. Numerous researchers $[6,7,20,21,24]$ have been investigating the performance of various FRCM and SRG in the last decade, and the findings allowed for developing acceptance criteria and design guidelines for this type of composite [9-11]. However, the available literature showed that each inorganicmatrix composite has peculiar properties that depend on several parameters (e.g., textile and matrix physical and mechanical properties and textile layout) and that are hard to estimate without proper experimental tests and analyses.

In this paper, the bond behavior of three FRCM composites and one SRG composite is investigated by means of single-lap direct shear tests on composite-masonry joints. The FRCM comprised a bidirectional carbon, PBO, or AR-glass textile, whereas the SRG comprised a unidirectional stainless-steel cord textile. Cement- and lime-based mortars were used as the matrix. For the PBO and carbon FRCM studied in this paper, other experimental investigations are available in the literature (see e.g., [25]). However, no other contributions are available regarding the AR-glass FRCM and the stainless-steel SRG considered. Based on the results obtained, an analytical procedure is used to solve the bond differential equation and model the behavior of the $\mathrm{PBO}$ and carbon FRCM using a trilinear cohesive material law (CML). Due to the specific failure mode observed in AR-glass FRCMand SRG-masonry joints, the analytical procedure could not be performed.

\section{Experimental Program}

Six masonry blocks with dimensions $120 \mathrm{~mm} \times 125 \mathrm{~mm} \times 380 \mathrm{~mm}$ were assembled using six half-bricks. Commercially available fired-clay bricks with dimension of $55 \mathrm{~mm}$ $\times 120 \mathrm{~mm} \times 250 \mathrm{~mm}$ were employed [26], whereas the $10 \mathrm{~mm}$ thick mortar joints were comprised of a pre-mixed cementitious mortar. The compressive strength, splitting strength, and elastic modulus of the bricks were determined in [27] by testing cylinders cored from the bricks and were 20.3,3.12, and $7300 \mathrm{MPa}$, respectively. The pre-mixed mortar had a 28-day compressive strength of $2.5 \mathrm{MPa}$, as declared by the manufacturer [28].

Three types of FRCM composites and one SRG composite were externally bonded to the masonry blocks. Four nominally equal specimens were tested for each type of composite. The FRCM composites comprised three different bidirectional textiles and two inorganic mortars (here referred to as matrices to prevent confusion with the mortar used to assemble the blocks). The first and second FRCM composite comprised carbon and PBO textiles, respectively, which were embedded within the same cement-based matrix [29]. The third FRCM composite included an AR-glass-coated textile embedded within a cementbased mortar. Finally, the SRG composite was comprised of a unidirectional stainless-steel cord textile embedded within a natural hydraulic lime NHL 5 matrix [30]. Figure 1 shows the four types of textiles considered in this study. While the carbon and PBO textiles have longitudinal and transversal yarns not threaded together, the AR-glass textile was obtained with the leno wave technique [31], where the transversal (weft) yarns pass through longitudinal (warp) yarns (Figure 1). Therefore, only in the AR-glass FRCM the transversal yarns may contribute to the composite capacity when the load is applied to the longitudinal yarns [32]. 


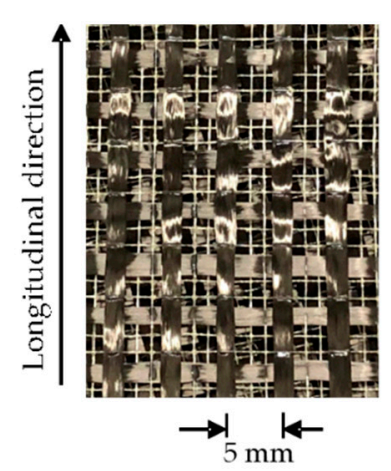

(a)

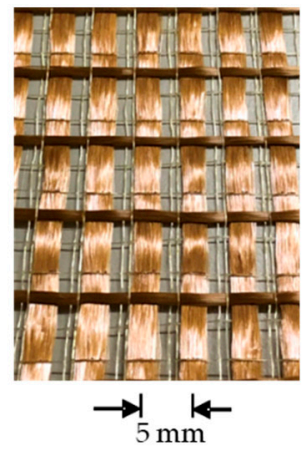

(b)

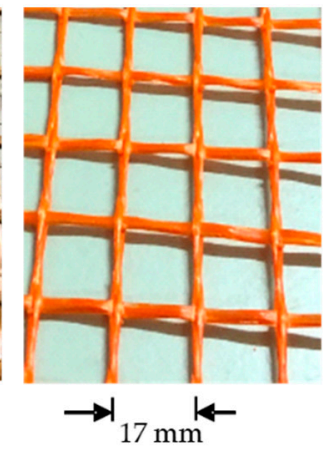

(c)

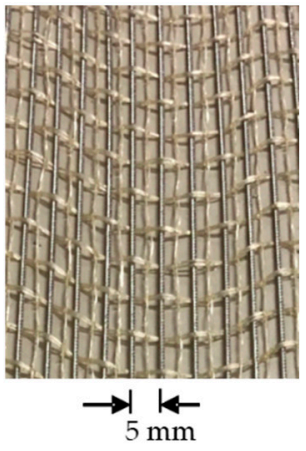

(d)

Figure 1. Fiber-reinforced cementitious matrix (FRCM) textiles: (a) carbon; (b) PBO (polyparaphenylene benzobisoxazole); (c) alkali-resistant (AR)-glass; (d) stainless steel.

The mechanical properties of the textiles and matrices are summarized in Table 1, where the properties of carbon and PBO textiles were measured by tensile tests as reported in $[21,25]$, respectively, while those of the steel textile were reported by the manufacturer [33]. The tensile strength and elastic modulus of the AR-glass textile were obtained by nine tensile tests on specimens comprising three longitudinal yarns according to [11] and were equal to $874 \mathrm{MPa}$ (coefficient of variation $(\mathrm{CoV})=0.078)$ and $65,300 \mathrm{MPa}(\mathrm{CoV}=0.221)$, respectively. Table 1 also reports the geometrical properties of the textile used. The carbon and PBO textile yarns were assumed to have a rectangular cross-section with width $b^{*}$ and thickness $t^{*}$. The steel cords and the AR-glass yarns were assumed to have circular cross-sections with diameter $d^{*}$.

Table 1. Mechanical properties of textiles and matrices.

\begin{tabular}{|c|c|c|c|c|c|c|c|c|c|}
\hline \multirow[b]{2}{*}{ Composite } & \multicolumn{6}{|c|}{ Textile Properties } & \multicolumn{3}{|c|}{ Matrix Properties } \\
\hline & $\begin{array}{c}d^{*} \\
{[\mathrm{~mm}]}\end{array}$ & $\begin{array}{c}b^{*} \\
{[\mathrm{~mm}]}\end{array}$ & $\begin{array}{c}t^{*} \\
{[\mathrm{~mm}]}\end{array}$ & $\begin{array}{c}f_{f} \\
{[\mathrm{MPa}]}\end{array}$ & $\begin{array}{c}E_{f} \\
{[\mathrm{GPa}]}\end{array}$ & $\varepsilon_{f}$ & $\begin{array}{c}f_{c} \\
{[\mathrm{MPa}]}\end{array}$ & $\begin{array}{c}f_{r} \\
{[\mathrm{MPa}]}\end{array}$ & $\begin{array}{c}E_{c}^{\dagger} \\
{[\mathrm{GPa}]}\end{array}$ \\
\hline $\begin{array}{l}\text { Carbon } \\
\text { FRCM }\end{array}$ & - & 5 & 0.094 & 1944 & 203 & 0.0095 & 25.0 & 6.1 & $>7.5^{\dagger}$ \\
\hline PBO FRCM & - & 5 & 0.092 & 3014 & 206 & 0.0145 & 25.0 & 6.2 & $>7.5^{\dagger}$ \\
\hline Glass FRCM & 1.11 & - & - & 874 & 65 & 0.0134 & 22.0 & 6.0 & $\sim 7.6^{+}$ \\
\hline $\mathrm{SRG}^{+}$ & 1.01 & - & - & $>2000$ & 210 & - & 10.0 & - & - \\
\hline
\end{tabular}

${ }^{\dagger}$ Provided by the manufacturer; $b^{*}$ : width of a fiber yarn; $d^{*}$ : diameter of a fiber yarn; $t^{*}$ : thickness of a fiber yarn $f_{f}$ : tensile strength of the textile; $E_{f}$ : textile elastic modulus; $\varepsilon_{f}$ : textile ultimate strain; $f_{c}$ : mean matrix compressive strength; $f_{r}$ : mean matrix flexural strength; $E_{c}$ : mean matrix elastic modulus.

\subsection{Specimen Preparation}

After being assembled, the masonry blocks were cured in a climatic chamber for 28 days at $25{ }^{\circ} \mathrm{C}$ and $90 \%$ RH. At the end of the curing period, the FRCM and SRG strips were applied to each face of the masonry block except that cut. The bonded length and width of each composite were $300 \mathrm{~mm}$ and $50 \mathrm{~mm}$, respectively. The bonded length was selected to be greater than the effective bond length reported in the literature for similar composites [21,34-36] and comply with that recommended by the Italian initial type testing procedure [11]. The width was selected to include at least three textile longitudinal yarns. The strips included $n=5$ longitudinal yarns for carbon, $n=5$ for PBO, $n=3$ for AR-glass, and $n=7$ for stainless-steel composites. The FRCM or SRG strips were applied to the block following these steps:

- The masonry block surface was wet with water to prevent absorption of the matrix water by the substrate.

- A first (internal) layer of matrix was applied to the substrate using plastic molds to control the bonded area and matrix layer thickness. The thickness of the layer was $5 \mathrm{~mm}$ as recommended by the manufacturer $[29,30,37]$. 
- A textile strip $630 \mathrm{~mm}$ long was gently pressed onto the internal matrix layer. The textile strip was left bare outside the loaded end for $310 \mathrm{~mm}$ and outside the free end for $20 \mathrm{~mm}$. The bonded length started $35 \mathrm{~mm}$ far from the masonry block edge at the loaded end to prevent the substrate wedge failure [11]. The specimen geometry is shown in Figure 2.

- Finally, a second (external) layer of matrix with the same dimension of the matrix internal layer was applied over the textile again using a plastic mold to control its geometry.

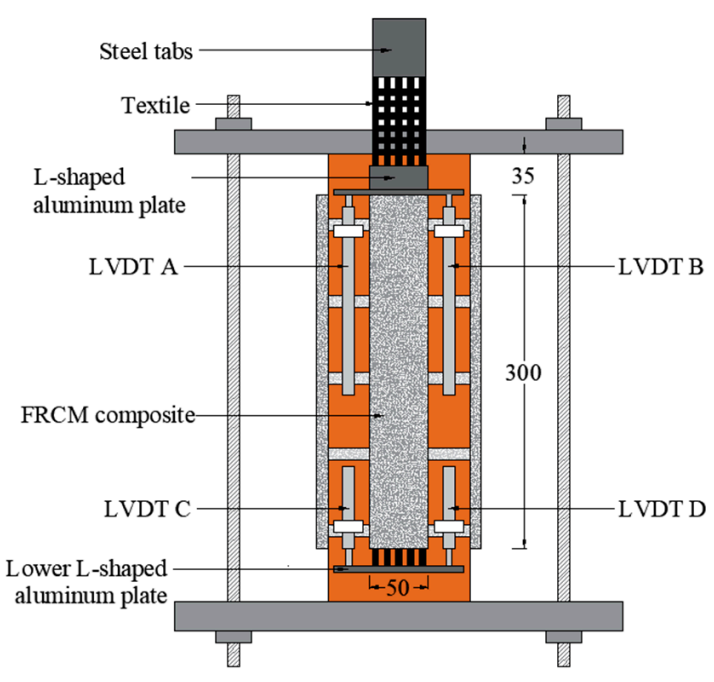

(a)

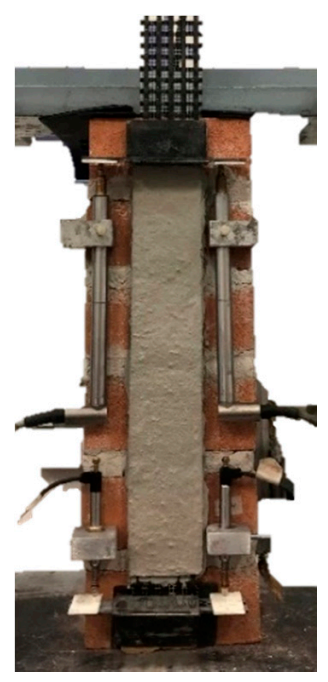

(b)

Figure 2. (a) Sketch of the single-lap shear test set-up (dimensions in $\mathrm{mm}$ ); (b) photo of specimen DS_300_50_C_1.

The specimens were left for $24 \mathrm{~h}$ in the lab conditions to allow an initial hardening of the matrix. Then, a composite strip was applied to the other two non-cut faces of the masonry block following the same procedure adopted for the first strip. The specimens were cured inside an environmental chamber for 28 days at $25^{\circ} \mathrm{C}$ and $90 \% \mathrm{RH}$.

\subsection{Single-Lap Direct Shear Test Set-Up}

A single-lap pull-push direct shear test (Figure 2) was employed in this study. The masonry block was restrained between two steel plates connected by four steel threaded bars. Two steel tabs were epoxy bonded to the end of the bare textile strip at the loaded end to promote gripping by the testing machine. Tests were conducted in displacement control by monotonically increasing the machine stroke at a rate of $0.2 \mathrm{~mm} / \mathrm{min}$ [11]. The relative displacement between the substrate and the bare fiber just outside the bonded length at the loaded end was measured using two Linear Variable Displacement Transducers (LVDTs) attached to the masonry block and reacting off of an L-shaped aluminum plate attached to the bare fiber just outside the bonded length (Figure 2). The average of the measures of these two LVDTs (A and B) is named global slip $g$ in this paper. Furthermore, two LVDTs (C and D) were attached to the masonry block at the free end and reacted off of an L-shaped aluminum plate attached at the end of the bare fibers at the free end (Figure 2). The average of LVDT C and D measures is named free end slip $s_{F}$ in this paper.

\section{Results and Discussion}

Specimens were named following the notation DS_300_50_X_n, where DS indicates the type of test (direct shear), 300 is the bonded length (in $\mathrm{mm}$ ), 50 is the bonded width $b_{1}$ (in $\left.\mathrm{mm}\right), X$ indicates the composite used $(\mathrm{C}=$ carbon FRCM, P $=$ PBO FRCM, $\mathrm{G}=$ AR-glass FRCM, $\mathrm{S}=\mathrm{SRG}$ ), and $n$ is the specimen number. The specimen tested are listed in 
Table 2, where the peak load $P^{*}$, corresponding average peak load $\bar{P}^{*}$, peak stress (or bond capacity) $\sigma^{*}$, corresponding average peak stress $\bar{\sigma}^{*}$, peak load per unit width $P_{b}^{*}=P^{*} / b_{1}$, corresponding average peak load per unit width $\bar{P}_{b}^{*}$, and failure mode FM are also reported. The bond capacity $\sigma^{*}$ was determined using Equation (1):

$$
\sigma^{*}=\frac{P^{*}}{n b^{*} t^{*}}
$$

where $n$ is the number of longitudinal yarns within the composite strip width. Four different modes of failure were observed in this study (Figure 3). Failure modes were indicated with the notation $Y_{Z}$, where $Y$ indicates the failure type $(D=$ debonding failure, $R=$ fiber rupture, $M=$ mixed failure) and the subscript $Z$ indicates where the failure occurred $(m=$ within the matrix, $s=$ within the substrate, $m s=$ at the matrix-substrate interface, and $m f=$ at the matrix-fiber interface). When mixed failure occurred, the order of the failure modes referred to in the notation indicates the order these modes occurred in the test. The first failure mode was debonding at the matrix-fiber interface $\left(D_{m f}\right)$, which was characterized by slippage of the textile within the matrix (Figure 3a). The second failure mode was debonding at the matrix-substrate interface $\left(D_{m s}\right)$ without damage of the substrate (Figure $3 \mathrm{~b}$ ). The third failure mode was a mixed debonding at the matrix-fiber interface followed by fiber rupture $\left(M D_{m f} R\right.$, see Figure $\left.3 c\right)$. The last failure mode was a mixed debonding at the matrixsubstrate interface and matrix-fiber interface $\left(M D_{m s} D_{m f}\right)$, which is often triggered by transverse cracking of the matrix (Figure 3d). More details on the failure modes are provided in the following Section 3.1.

Table 2. Direct shear test results for the FRCM.

\begin{tabular}{|c|c|c|c|c|c|c|c|}
\hline Specimen Name & $\begin{array}{c}P^{*} \\
{[\mathrm{kN}]}\end{array}$ & $\begin{array}{c}\overline{\boldsymbol{P}}^{*} \\
{[\mathrm{kN}]}\end{array}$ & $\sigma^{*}[\mathrm{MPa}]$ & $\bar{\sigma}^{*}[\mathrm{MPa}]$ & $P_{b}^{*}[\mathrm{kN} / \mathrm{m}]$ & $\bar{P}_{b}^{*}[\mathrm{kN} / \mathrm{m}]$ & FM \\
\hline DS_300_50_C_1 & 2.42 & \multirow{4}{*}{$\begin{array}{c}2.37 \\
(8.70)\end{array}$} & 1030 & \multirow{4}{*}{$1010(8.70)$} & 48.4 & \multirow{4}{*}{$47.5(8.70)$} & $M D_{m s} D_{m f}$ \\
\hline DS_300_50_C_2 & 2.46 & & 1047 & & 49.2 & & $D_{m f}$ \\
\hline DS_300_50_C_3 & 2.58 & & 1098 & & 51.6 & & $D_{m f}$ \\
\hline DS_300_50_C_4 & 2.03 & & 864 & & 40.6 & & $D_{m f}$ \\
\hline DS_300_50_P_1 & 5.67 & \multirow{4}{*}{$\begin{array}{c}4.80 \\
(13.68)\end{array}$} & 2465 & \multirow{4}{*}{$2086(13.68)$} & 113.4 & \multirow{4}{*}{$96.0(13.68)$} & $D_{m f}$ \\
\hline DS_300_50_P_2 & 4.66 & & 2026 & & 93.2 & & $D_{m f}$ \\
\hline DS_300_50_P_3 & 5.01 & & 2178 & & 100.2 & & $D_{m f}$ \\
\hline DS_300_50_P_4 & 3.85 & & 1674 & & 77.0 & & $D_{m f}$ \\
\hline DS_300_50_G_1 & 1.77 & \multirow{4}{*}{$\begin{array}{c}1.85 \\
(6.43)\end{array}$} & 617 & \multirow{4}{*}{$643(6.43)$} & 35.4 & \multirow{4}{*}{$36.9(6.43)$} & $M D_{m f} R$ \\
\hline DS_300_50_G_2 & 1.69 & & 589 & & 33.8 & & $M D_{m f} R$ \\
\hline DS_300_50_G_3 & 1.95 & & 679 & & 39.0 & & $M D_{m f} R$ \\
\hline DS_300_50_G_4 & 1.97 & & 686 & & 39.4 & & $M D_{m f} R$ \\
\hline DS_300_50_S_1 & 4.36 & \multirow{4}{*}{$\begin{array}{c}5.14 \\
(9.47)\end{array}$} & 778 & \multirow{4}{*}{$916(9.47)$} & 87.2 & \multirow{4}{*}{$102.7(9.47)$} & $D_{m s}$ \\
\hline DS_300_50_S_2 & 5.28 & & 942 & & 105.6 & & $D_{m s}$ \\
\hline DS_300_50_S_3 & 5.2 & & 928 & & 104 & & $M R D_{m f}$ \\
\hline DS_300_50_S_4 & 5.7 & & 1017 & & 114 & & $M R D_{m f}$ \\
\hline
\end{tabular}




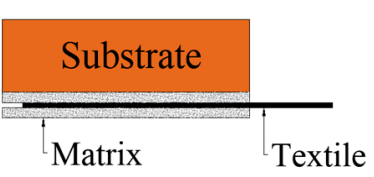

(a)

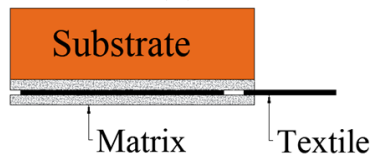

(c)

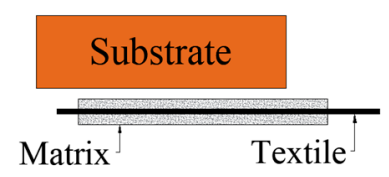

(b)

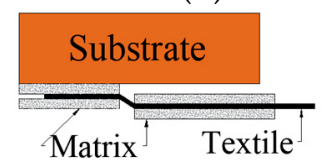

(d)

Figure 3. Failure modes observed: (a) debonding at the matrix-fiber interface $\left(D_{m f}\right)$; (b) debonding at the matrix-substrate interface $\left(D_{m s}\right) ;(\mathbf{c})$ mixed debonding at the matrix-fiber interface and fiber rupture $\left(M D_{m f} R\right)$; (d) mixed debonding at the matrix-substrate and matrix-fiber interfaces $\left(M D_{m s} D_{m f}\right)$.

\subsection{Bond Performance of Carbon FRCM-Masonry Joints}

Two failure modes were observed in carbon FRCM-masonry joints. All specimens except DS_300_50_C_1 failed due to debonding at the matrix-fiber interface $\left(D_{m f}\right)$. This failure mode was characterized by slippage of the textile yarns within the matrix without any visible crack on the matrix except for specimen DS_300_50_C_4, in which a longitudinal crack occurred between the internal and external layers of the matrix, as shown in Figure 4a. This crack is usually referred to as an interlaminar matrix crack [36]. Specimen DS_300_50_C_1 showed a mixed debonding failure at the matrix-substrate and at the matrix-fiber interfaces $\left(M D_{m s} D_{m f}\right)$, as shown in Figure $4 \mathrm{~b}$. This type of failure was previously observed in SRG-masonry joints tested by Franzoni et al. [6].
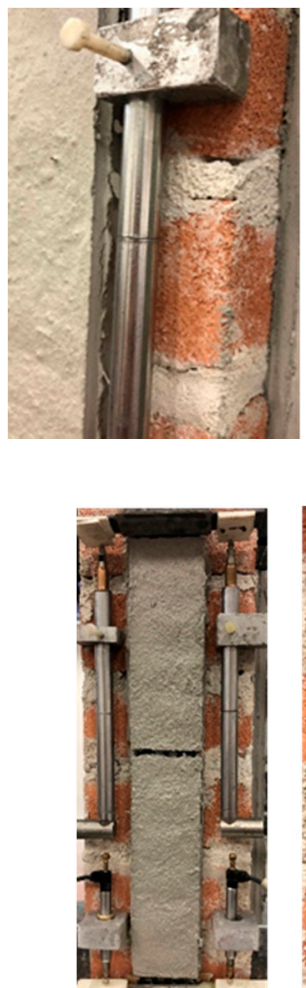

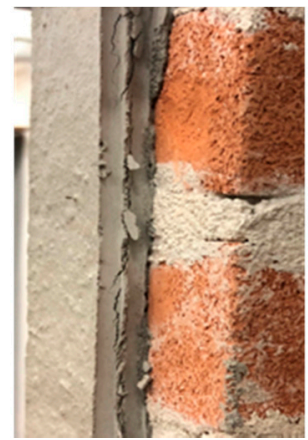

(a)

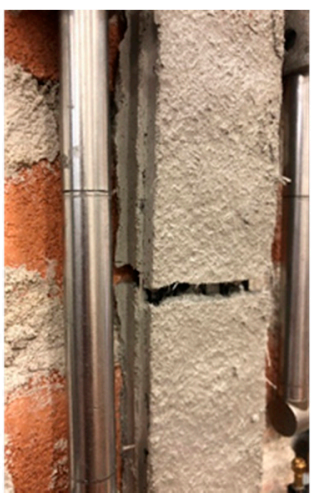

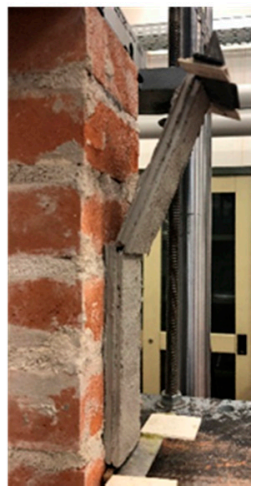

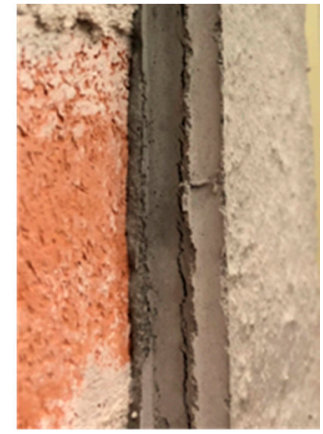

(b)

Figure 4. Failure modes of carbon FRCM: (a) interlaminar matrix crack in specimen DS_300_50_C_3; (b) mixed debonding failure $\left(M D_{m s} D_{m f}\right)$ of specimen DS_300_50_C_1. 
Figure 5a presents the applied load $P$-global slip $g$ response of the carbon FRCMmasonry joint. Specimen DS_300_50_C_1 showed an initial linear P-g response (Figure 5a). At the end of the linear branch (approximately $81 \%$ of the peak load), a small load drop was observed due to the occurrence of a matrix transversal crack approximately at the middle of the composite bonded length (Figure $4 \mathrm{~b}$ ). After that, the upper part of the composite (i.e., close to the loaded end) debonded from the masonry substrate (Figure $4 b$ ), whereas the lower part remained bonded to it. With increasing $g$, the load increased further until the peak load $P^{*}$ was attained. At $P^{*}$, the stress transfer zone (STZ), which is the zone along which the bond stress is transferred [21], had already attained the free end, as indicated by the non-zero values of $s_{F}$ (Figure $5 \mathrm{~b}$ ). A further increase of the global slip after $P^{*}$ led to a decrease of the applied load until complete matrix-fiber debonding in the lower portion of the strip still attached to the substrate, which was associated with a constant applied load due to friction (interlocking) among the fiber filaments and between fibers and the matrix $[21,38]$.

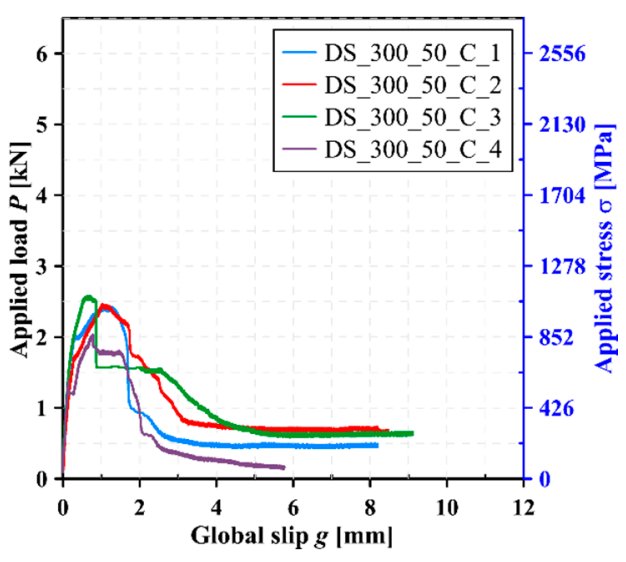

(a)

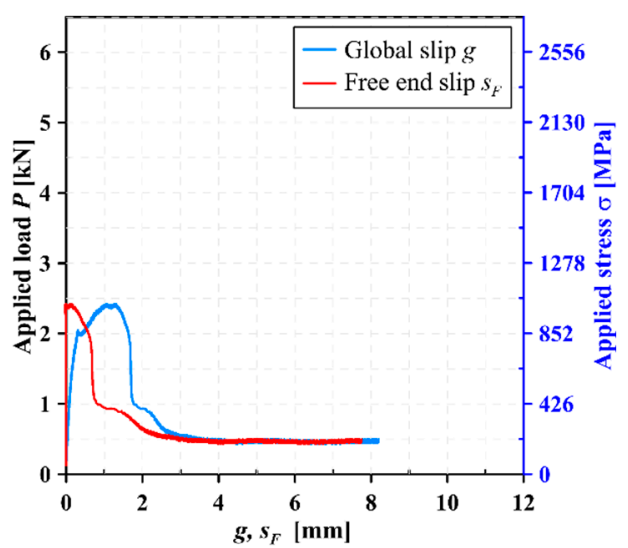

(b)

Figure 5. Carbon FRCM-masonry joints: (a) applied load $P$-global slip $g$ response; (b) load response of specimen DS_300_50_C_1.

The load response of specimens DS_300_50_C_2-4 resembled that of specimen DS_300_ 50_C_1. The initial linear behavior ended at approximately $70 \%$ of the peak load (Figure 5a), when micro-cracking started to occur at the matrix-fiber interface. Then, after the peak load was attained, the $P$ - $g$ curve showed a softening branch and a final residual applied load. For specimen DS_300_50_C_4, the applied load did not attain a constant value at the end of the test (Figure 5a). This behavior might be attributed to the occurrence of the matrix interlaminar crack in this specimen.

\subsection{Bond Performance of PBO FRCM-Masonry Joints}

All specimens with PBO FRCM composite failed due to debonding at the matrixfiber interface $\left(D_{m f}\right)$, as generally reported in the literature for composites comprising PBO fibers $[24,34]$. The debonding, which determined the increasing slip of the fibers within the matrix, was characterized by the occurrence of several transversal cracks in the matrix external layer. These cracks eventually propagated toward the substrate and, except for specimen DS_300_50_P_2, determined the opening of a longitudinal crack at the internal-external matrix layer interface (matrix interlaminar crack), which in turn led to the detachment of the matrix external layer (Figure 6). 

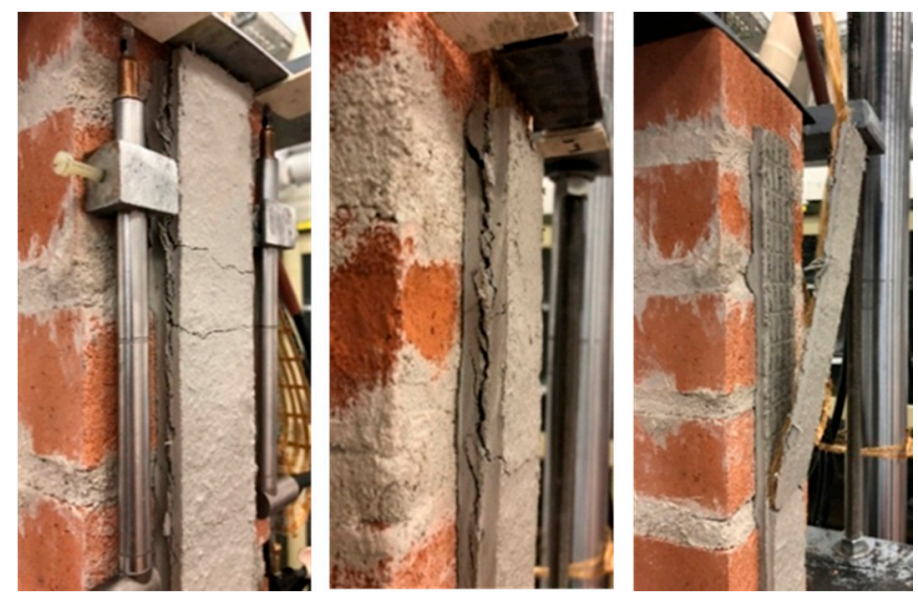

Figure 6. Failure of specimen DS_300_50_P_3.

The $P-g$ responses of specimens with the PBO FRCM composite are shown in Figure 7a. All specimens showed an initial linear elastic branch followed by a non-linear response up to the peak load. Then, the applied load decreased until the test was interrupted after complete debonding of the textile. Figure $7 \mathrm{~b}$ shows that the free end slip $s_{F}$ started assuming non-zero values slightly before $P^{*}$ was attained, which indicates that the STZ attained the free end, as observed for carbon FRCM-masonry joints. After the initial elastic branch, all specimens except DS_300_50_P_2 showed sudden drops of the applied load associated with the opening of matrix transversal cracks (Figure 7).

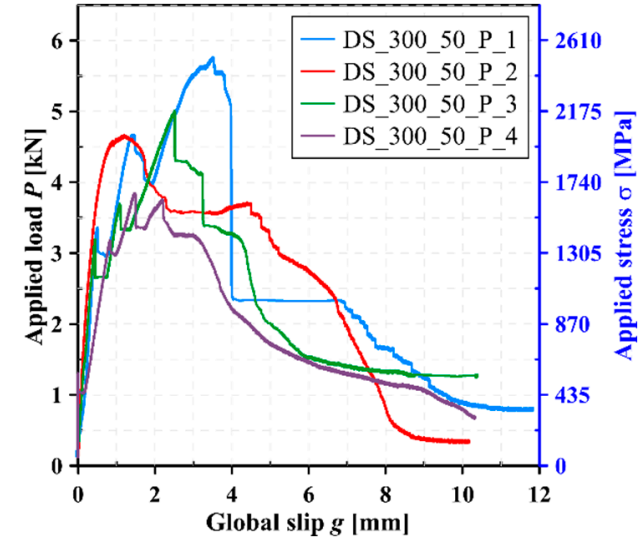

(a)

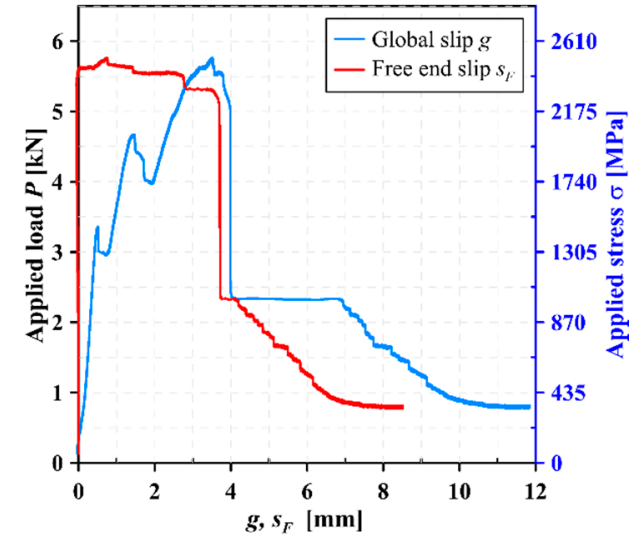

(b)

Figure 7. PBO FRCM-masonry joints: (a) applied load $P$-global slip $g$ response; (b) load response of specimen DS_300_50_P_1.

At the end of the test, the applied load of specimen DS_300_50_P_4 did not show a constant residual applied stress, whereas the remaining specimens attained different constant applied load values. These differences can be attributed to the occurrence of the matrix transversal cracks.

\subsection{Bond Performance of AR-Glass FRCM-Masonry Joints}

Specimens with AR-glass FRCM composite failed due to debonding at the matrix-fiber interface followed by rupture of the textile yarns within the bonded length close to the loaded end $\left(M D_{m f} R\right)$, as shown in Figure 8. 


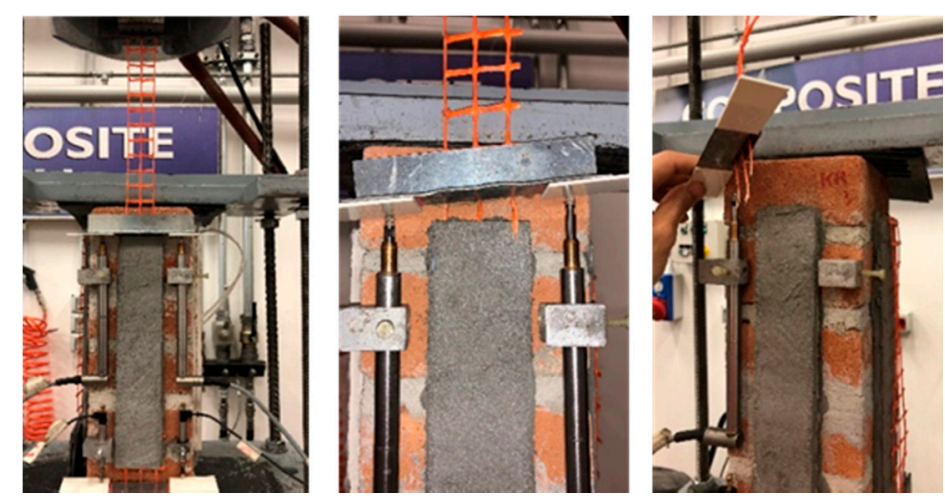

Figure 8. Failure mode of glass FRCM-masonry joints.

The $P-g$ responses are presented in Figure 9a. After the initial linear elastic branch, the slope of the $P-g$ curves decreased due to micro-cracking at the matrix-fiber interface. The applied load increased with increasing $g$ until a load drop occurred (Figure 9a). After this first load drop, which could be attributed to the rupture of some fiber filaments, the applied load decreased in all specimens except in specimen DS_300_50_G_4, and subsequent rupture of other fiber bundles determined further load drops until the test was interrupted. In specimen DS_300_50_G_4, a significant slope decrease was observed at approximately $1.6 \mathrm{kN}$ (Figure 9), after which the applied load only slightly increased with increasing the global slip. This behavior can be attributed to slippage of the textile, which was followed by eventual rupture of some fiber bundles as observed by the load drops in the descending portion of the load response. These load drops might also be associated with failure of warp-weft yarn nodes, which were obtained with the leno wave technique in the AR-glass textile (Section 2). However, this could not be verified, because it was not possible to remove the external matrix layer without damaging the embedded textile.

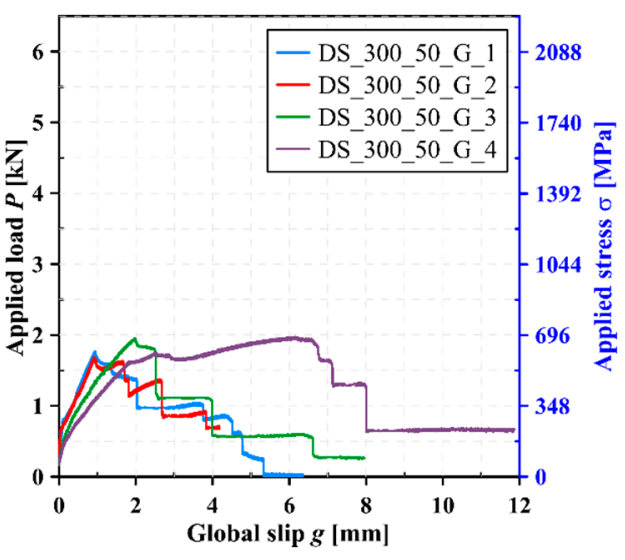

(a)

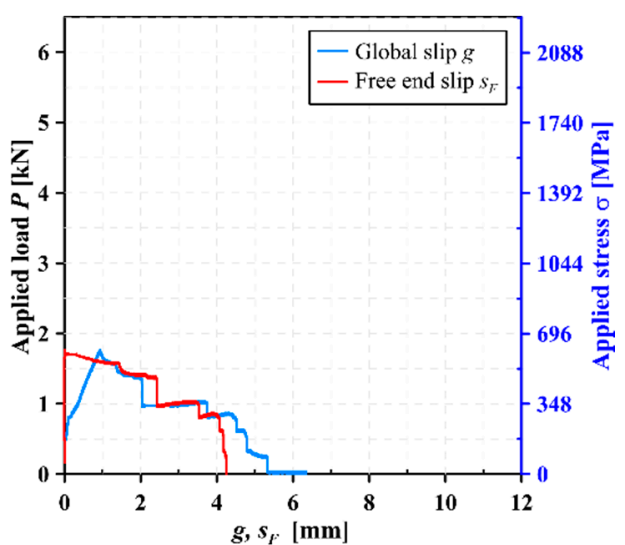

(b)

Figure 9. AR-glass FRCM-masonry joints: (a) applied load $P$-global slip $g$ response and (b) load response of specimen DS_300_50_G_1.

For all specimens, non-zero values of the free end slip $s_{F}$ were observed slightly before the attainment of the peak load $P^{*} . s_{F}$ increased with increasing $g$ after $P^{*}$ (see e.g., Figure $9 \mathrm{~b}$ ), which indicates that debonding of the fiber from the matrix along the entire bonded length occurred. However, some textile yarns eventually ruptured for high values of $g$, which did not allow for measuring a reliable residual applied stress for all specimens. 


\subsection{Bond Performance of SRG-Masonry Joints}

Specimens with SRG reported two different failure modes. Specimens DS_300_50_S_1 and 2 failed due to the sudden debonding of the entire composite strip at the matrixsubstrate interface $\left(D_{m s}\right)$, as shown in Figure 10a. The remaining specimens (DS_300_50_S_3 and 4) reported mixed rupture of some steel cords at the loaded end and debonding at the matrix-fiber interface $\left(M R D_{m f}\right)$, as shown in Figure 10b.

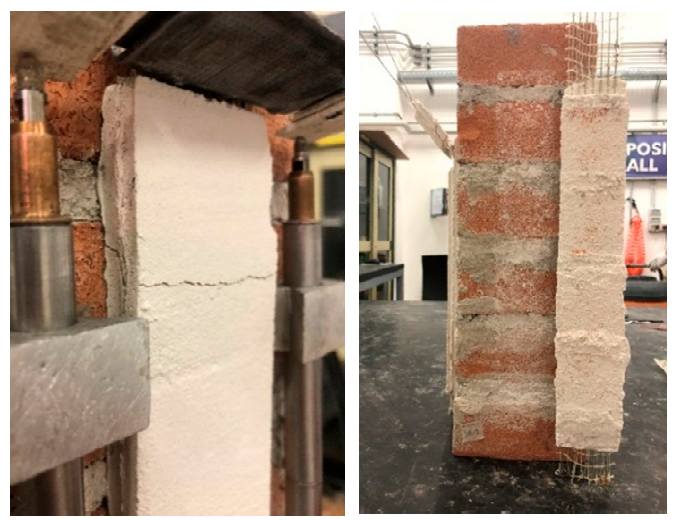

(a)
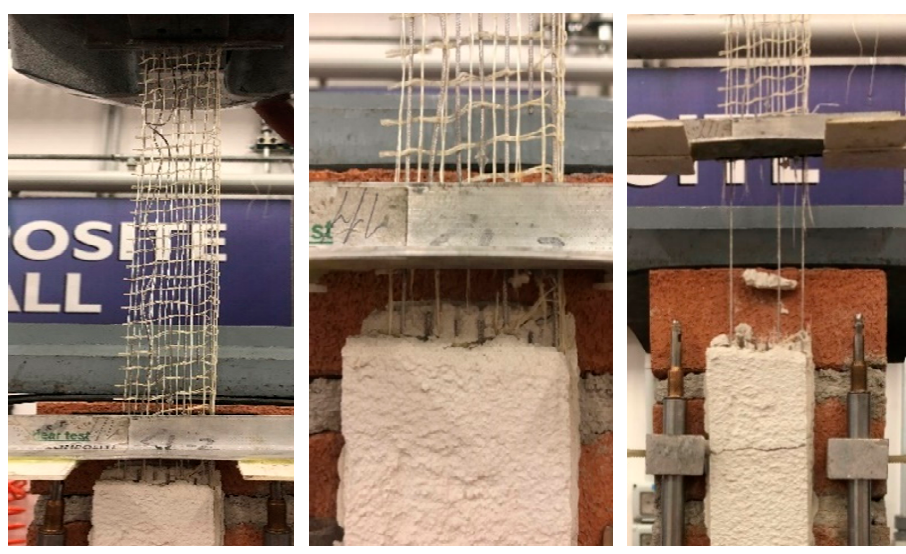

(b)

Figure 10. (a) Detachment of the entire steel-reinforced grout (SRG) strip in specimen DS_300_50_S_1; (b) rupture of steel cords and slippage of the remaining cords in specimen DS_300_50_S_3.

The $P-g$ responses of specimens with SRG are shown in Figure 11a. Two types of response were observed depending on the failure mode. When complete detachment of the composite strip occurred (specimens DS_300_50_S_1 and 2), the load response was approximately linear until the peak load, when failure occurred (Figure 11a). The slight non-linearity observed in the $P$ - $g$ curve can be attributed to micro-cracking at the matrixfiber interface and consequent matrix-fiber debonding close to the loaded end, as also indicated by matrix transversal cracks (Figure 11a). However, complete debonding of the fiber from the matrix did not occurred, as confirmed by null free end slip for the entire test. 


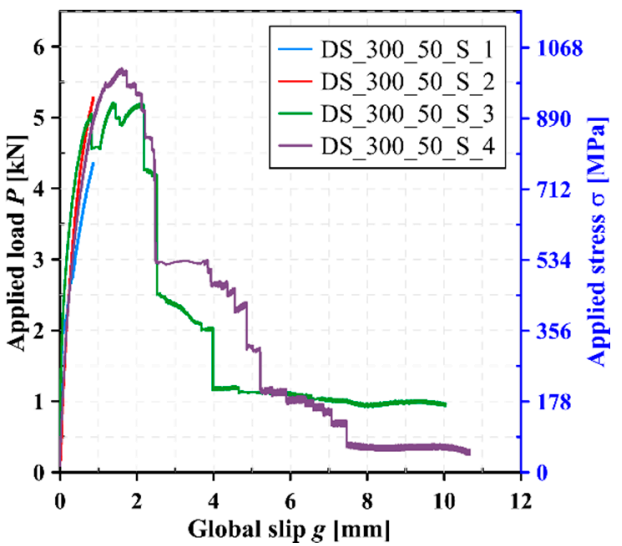

(a)

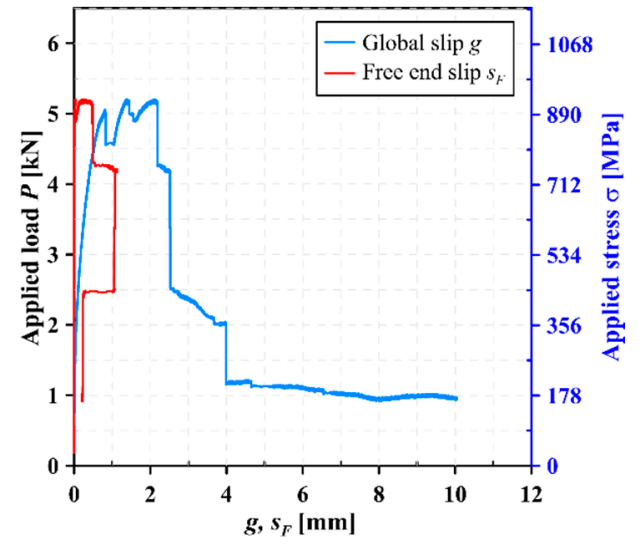

(b)

Figure 11. SRG-masonry joints: (a) applied load $P$ —global slip $g$ response and (b) load response of specimen DS_300_50_S_3.

When fiber rupture occurred (specimens DS_300_50_S_3 and 4), the ascending part of the load responses resembled those of specimen DS_300_50_S_1 and 2. At the peak load, matrix-fiber debonding was fully developed and the STZ attained the free end, as confirmed by non-zero $s_{F}$ values in Figure $11 \mathrm{~b}$. The $P-g$ descending branch was characterized by sudden load drops associated with rupture of one or more steel cords. Eventually, the remaining cords completely debonded from the embedding matrix and a residual applied load, attributed to the presence of friction at the matrix-fiber interface, was observed.

\subsection{Comparison of the Bond Performance for the Various Composite Systems}

In this section, the bond capacity of the different composites is analyzed to provide an indication on their performance. However, it should be noted that FRCM comprising different fibers and matrices should not be compared only in terms of their bond capacity or peak load per unit width. In fact, numerous parameters are considered when selecting a certain FRCM or SRG composite for a specific application. Among them, important parameters are the composite stiffness, strength, cost, compatibility with the substrate, and textile layout (unidirectional, bidirectional, and multidirectional).

Figure 12a compares the average bond capacity of the FRCM and SRG composites in Table 2, along with the corresponding standard deviation (indicated with error bars). The average bond capacity $\bar{\sigma}^{*}$ (see Equation (1)) ranged between $636 \mathrm{MPa}$ for the ARglass FRCM and $2109 \mathrm{MPa}$ for the PBO FRCM (Table 2). The coefficient of variation (CoV) varied between 6.4\% (AR-glass FRCM) and 13.7\% (PBO FRCM). This value (scatter) can be considered acceptable given the sensitivity of FRCM and SRG composites to the manufacturing, curing, and handling [22]. In order to compare the composite capacity, the capacity (peak load) per unit width can be considered. Figure 12b compares the average peak load per unit width $\bar{P}_{b}^{*}$ listed in Table 2, along with the corresponding standard deviation (again indicated with error bars). The peak load per unit width ranges between $37 \mathrm{kN} / \mathrm{m}$ for the AR-glass composite and $103 \mathrm{kN} / \mathrm{m}$ for the SRG (Table 2). Clearly, the different cross-sectional area of each textile determined a completely different peak load per unit width. 


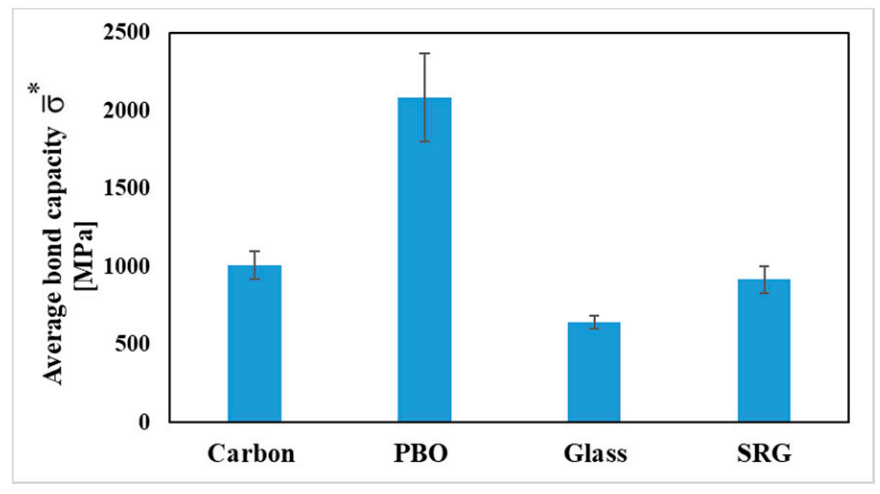

(a)

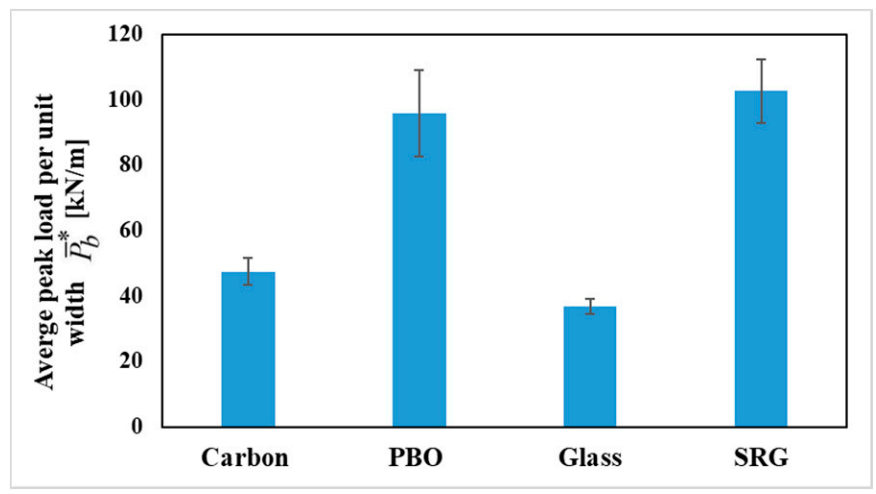

(b)

Figure 12. Comparison of the (a) average bond capacity and (b) average peak load per unit width for the composites studied.

Finally, the comparison of results in Figure 12a and the tensile strength of bare textiles in Table 1 shows that the exploitation ratio (i.e., the ratio between the average bond capacity and the textile tensile strength) is significantly less than 1.0 for all composites. The highest value is achieved by the AR-glass (0.74), while the lowest value is provided by the SRG $(<0.46)$. Carbon and PBO have an exploitation ratio equal to 0.57 and 0.69 , respectively.

\section{Analytical Study}

In this section, the results described in Section 3 are modeled using the analytical approach developed in [39]. In particular, a trilinear cohesive material law (CML), which relates the slip $s$ and corresponding shear stress $\tau$ at the interface where slip occurs, is adopted to describe the bond behavior of FRCM-masonry joints. To properly calibrate the CML, a $P$ - $g$ response associated with debonding at the matrix-fiber or matrix-substrate interface should be used. Therefore, the analytical approach is employed to model the response of the carbon and PBO FRCM, for which failure due to debonding at the matrix-fiber interface occurred. In fact, the glass FRCM and the SRG showed fibers rupture and mixed mode failures. Although a calibration of the CML would be possible in any case, further tests with different bonded lengths should be carried out to clearly understand the effect of fiber rupture and mixed mode failure and obtain a reliable calibration of the CML for the glass FRCM and the SRG employed.

The trilinear CML (Figure 13a) is comprised of an elastic branch followed by a linear softening branch and a final horizontal friction branch. The elastic branch has slope $k_{1}$ and ends when the maximum interface strength $\tau_{\max }$ is attained (or equivalently when the slip $s_{0}$ is achieved). The softening branch has slope $k_{2}$ and ends when the shear stress attains $\tau_{f}$ (or equivalently when the slip achieves $s_{f}$ ). A trilinear CML was employed to study the bond behavior of $\mathrm{PBO}$-concrete joints and allowed for an accurate modeling 
of the corresponding load response [39]. Simpler CML were also employed (e.g., bilinear elasto-fragile [40] or rigid-softening [41]). Although these CML can be easily calibrated, their simple shape entails for less accurate load responses with respect to those obtained with a trilinear CML.

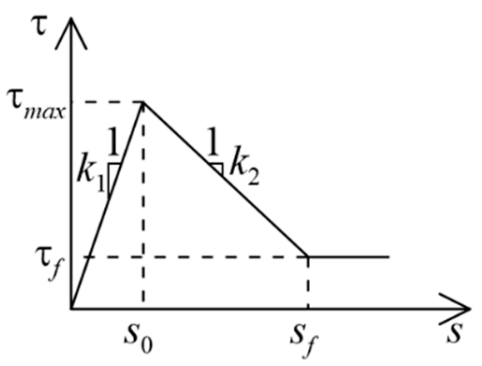

(a)

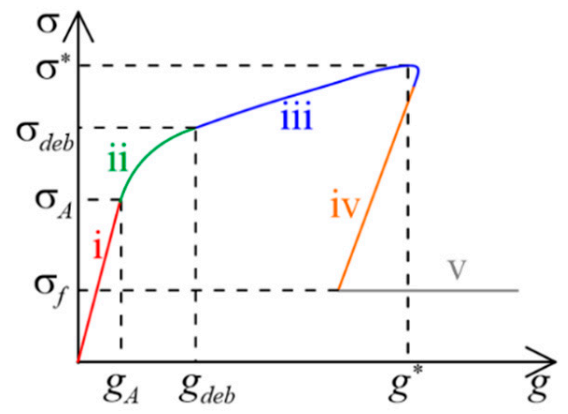

(b)

Figure 13. (a) Trilinear CML; (b) representative fiber applied stress $\sigma$-global slip $g$ response for long bonded length.

\subsection{Governing Equations}

To obtain the governing equations of the problem, we assume pure Mode-II loading condition at the matrix-fiber interface, negligible deformation of the matrix and substrate, no composite width effect, and linear elastic behavior of the textile [21,42]. The carbon and PBO textiles adopted in this study were assumed to have yarns with a rectangular cross-section with a width $b^{*}$ much larger than the corresponding thickness $t^{*}$ (i.e., $p \cong 2 b^{*}$, where $p$ is the matrix-fiber contact perimeter of a single yarn). Namely, $b^{*}=5 \mathrm{~mm}$ for both textiles, $t^{*}=0.094 \mathrm{~mm}$ for the carbon textile, and $t^{*}=0.092 \mathrm{~mm}$ for the PBO textile (Table 1 ). Considering the assumptions above, the bond differential equation that describes the shear $\tau(y)$ and slip $s(y)$ distribution at the matrix-fiber interface [39] is:

$$
\frac{\mathrm{d}^{2} s}{\mathrm{~d} y^{2}}-\frac{2}{E_{f} t^{*}} \tau=0
$$

where $E_{f}$ is the textile Young's modulus (see Section 2) and $y$ is the coordinate along the bonded length $\ell$ with the origin of the reference system located at the composite free end (i.e., $y=0$ at the free end, $y=\ell$ at the loaded end). Solving Equation (2) with a certain CML and enforcing appropriate boundary conditions [39] provides the interface shear stress $\tau(y)$, fiber axial strain $\varepsilon(y)$ (or equivalently fiber applied stress $\sigma(y)=E_{f} \varepsilon(y)$ ), and slip $s(y)$ for each point of the load response.

Considering an FRCM-masonry joint with a (relatively) long bonded length, i.e., a bonded length higher than the minimum length needed to fully establish the bond stress transfer mechanism (i.e., the effective bond length $l_{\text {eff }}$ [43]), the load response can be divided in five stages (Figure 13b): (i) elastic, (ii) elastic-softening, (iii) elastic-softening debonding, (iv) softening-debonding, and (v) fully debonded stage. The solutions of Equation (2) for each of these stages are reported in Table 3. 
Table 3. Solution of Equation (2) for the different stages of Figure 13b.

\begin{tabular}{|c|c|}
\hline \multicolumn{2}{|l|}{ Elastic stage (i) } \\
\hline$s(y)=\frac{\sigma t^{*} \lambda}{2 k_{1}} \frac{\cosh (\lambda y)}{\sinh (\lambda \ell)} ; \varepsilon(y)=\frac{\sigma t^{*} \lambda^{2}}{2 k_{1}} \frac{\sinh (\lambda y)}{\sinh (\lambda \ell)} ; \tau(y)=\frac{\sigma t^{*} \lambda}{2} \frac{\cosh (\lambda y)}{\sinh (\lambda \ell)}$ & $0 \leq y \leq \ell$ \\
\hline \multicolumn{2}{|l|}{ Elastic-softening stage (ii) } \\
\hline $\begin{array}{c}s(y)=s_{0}\left\{\frac{\lambda}{\omega} \tanh [\lambda(\ell-l)] \sin [\omega(y-\ell+l)]-\frac{k_{1}}{k_{2}} \cos [\omega(y-\ell+l)]+\frac{k_{1}+k_{2}}{k_{2}}\right\} \\
\varepsilon(y)=\omega s_{0}\left\{\frac{\lambda}{\omega} \tanh [\lambda(\ell-l)] \cos [\omega(y-\ell+l)]+\frac{k_{1}}{k_{2}} \sin [\omega(y-\ell+l)]\right\} \\
\tau(y)=-\tau_{\max }\left\{\frac{\omega}{\lambda} \tanh [\lambda(\ell-l)] \sin [\omega(y-\ell+l)]-\cos [\omega(y-\ell+l)]\right\}\end{array}$ & $\ell-l \leq y \leq \ell$ \\
\hline \multicolumn{2}{|l|}{ Elastic-softening-debonding stage (iii) } \\
\hline $\begin{array}{c}s(y)=\frac{\tau_{f}}{E_{f} t^{*}}\left(y^{2}-2 \ell y+l^{2}-d^{2}\right)+\frac{\sigma}{E_{f}}(y-\ell+d)+s_{f} \\
\varepsilon(y)=\frac{2 \tau_{f}}{E_{f} t^{*}}(y-\ell)+\frac{\sigma}{E_{f}} ; \tau(x)=\tau_{f}\end{array}$ & $\ell-d \leq y \leq \ell$ \\
\hline \multicolumn{2}{|l|}{ Softening-debonding stage (iv) } \\
\hline $\begin{aligned} s(y)= & \frac{\omega}{k_{2}}\left(\tau_{f} d-\frac{\sigma t^{*}}{2}\right) \frac{\cos (\omega y)}{\sin [\omega(\ell-d)]}+\tau_{\max } \frac{k_{1}+k_{2}}{k_{1} k_{2}} \\
& \varepsilon(y)=\frac{\omega^{2}}{k_{2}}\left(\frac{\sigma t^{*}}{2}-\tau_{f} d\right) \frac{\sin (\omega y)}{\sin [\omega(\ell-d)]} \\
& \tau(y)=\omega\left(\frac{\sigma t^{*}}{2}-\tau_{f} d\right) \frac{\cos (\omega y)}{\sin [\omega(\ell-d)]}\end{aligned}$ & $0 \leq y \leq \ell-d$ \\
\hline \multicolumn{2}{|l|}{ Fully debonded stage (v) } \\
\hline $\begin{array}{c}s(y)=\frac{\tau_{f}}{E_{f} t^{*}}\left(y^{2}-2 \ell y\right)+\frac{\sigma}{E_{f}} y+s_{f} \\
\varepsilon(y)=\frac{2 \tau_{f}}{E_{f} t^{*}}(y-\ell)+\frac{\sigma}{E_{f}} \\
\tau(y)=\tau_{f}\end{array}$ & $0 \leq y \leq \ell$ \\
\hline
\end{tabular}

Note: $\omega=\sqrt{2 k_{2} /\left(E_{f} t^{*}\right)} ; \lambda=\sqrt{2 k_{1} /\left(E_{f} t^{*}\right)} ; E_{f}=$ textile Young's modulus; $t^{*}=$ thickness of a yarn; $k_{1}, k_{2}, s_{f}$, and $\tau_{f}$ are parameters of the CML (see Figure 13b).

In the first stage (i), the interface response is elastic along the whole bonded length. The fiber applied stress $\sigma(\ell)$ and the global slip $s(\ell)$ at the loaded end at the end of this stage are named $\sigma_{A}$ and $g_{A}$, respectively. As the shear stress at the loaded end overcomes $\tau_{\max }$ and starts decreasing according to the softening behavior of the $C M L$, the response becomes non-linear, and stage (ii) (elastic-softening stage) begins. During this stage, a portion of interface of length $l$ is associated with the softening branch while the remaining portion of length $\ell-l$ is associated with the elastic branch of the CML. The fiber applied stress at the end of this phase is the debonding stress $\sigma_{d e b}$. In stage (iii) (elastic-softening debonding stage), a portion of the interface of length $d$ is debonded but still capable to provide an applied stress at the loaded end equal to $2 \tau_{f} d / t^{*}$. The remaining part of the interface is associated with the elastic-softening stage, where $l$ is the length of the portion associated with the CML softening branch and $\ell-l-d$ is that associated with the CML elastic branch. In stage (iv) (softening-debonding stage), no portion of the interface is associated with the CML elastic branch, the length of the debonded portion is $d$, and the remaining portion with length $\ell-d$ is associated with the CML softening branch. The fiber applied stress at the end of this phase is due to friction only and is equal to the friction stress $\sigma_{f}=2 \tau_{f} \ell / t^{*}$. Finally, in the last stage (v), the entire interface is debonded, and the fiber axialstress is constant and equal to $\sigma_{f}$ while the global slip increases.

\subsection{Evaluation of the Effective Bond Length}

Since the bond stress transfer mechanism is associated with the elastic-softening stage (ii), the effective bond length $l_{\text {eff }}$ can be computed by equating the loaded end slip in stage (ii) (see Table 3) to $s_{f}$ :

$$
l_{e f f}=l+\frac{1}{\lambda} \arctan \left[\frac{\lambda}{\omega \sin (\omega l)} \cdot\left(\cos (\omega l)-\tau_{f} / \tau_{\max }\right)\right] .
$$


Since the adopted CML requires an infinite bonded length to fully develop the elastic stage [44], $l$ (i.e., the length of the softening portion) can be evaluated by enforcing an applied stress for $\ell=l_{\text {eff }}$ equal to a certain fraction $\alpha$ of the applied stress associated with an infinite bonded length $[39,45,46]$ :

$$
l=\frac{2}{\omega} \arctan \left[\frac{\alpha \omega / \xi-\sqrt{\left(\tau_{f} / \tau_{\max }\right)^{2}+(\alpha \omega / \xi)^{2}-1}}{\tau_{f} / \tau_{\max }+1}\right]
$$

where:

$$
\xi=\frac{\omega}{\sqrt{1+\omega^{2} / \lambda^{2}}}
$$

\subsection{Estimation of the CML Parameters}

To fully define the trilinear CML, which is characterized by four of the parameters $s_{0}$, $\tau_{\max }, s_{f}, \tau_{f}, k_{1}, k_{2}$, and the area below the elastic-softening branch (i.e., the fracture energy $G_{F}=0.5\left[s_{f}\left(\tau_{\max }+\tau_{f}\right)-\tau_{f} s_{0}\right]$, see Figure 13a), four conditions are needed [39]. Among the possible strategies to define these conditions, in this paper, the parameters of the CMLs were calibrated by enforcing (see Figure 13b) the applied stress $\sigma_{A}$ and corresponding global slip $g_{A}$ at the end of the elastic stage (i), the debonding stress $\sigma_{d e b}$, and the friction stress $\sigma_{f}$ (Figure $13 b$ ). The average of these parameters identified on load responses in Figures 5 and 7 allowed for calibrating the CML for the carbon and PBO FRCM, respectively. The shear stresses $\tau_{\max }$ and $\tau_{f}$ and corresponding slips $s_{0}$ and $s_{f}$ obtained for the two CMLs are reported in Table 4.

Table 4. Parameters of the trilinear cohesive material laws (CMLs) for carbon and PBO FRCM.

\begin{tabular}{cccccccc}
\hline & $\begin{array}{c}s_{0} \\
{[\mathbf{m m}]}\end{array}$ & $\begin{array}{c}\tau_{\max } \\
{[\mathbf{M P a}]}\end{array}$ & $\begin{array}{c}s_{f} \\
{[\mathbf{m m}]}\end{array}$ & $\begin{array}{c}\tau_{f} \\
{[\mathbf{M P a}]}\end{array}$ & $\begin{array}{c}G_{F} \\
{\left[\mathbf{N} / \mathbf{m m}^{3}\right]}\end{array}$ & $\begin{array}{c}l_{\text {eff }} \text { [Equation (3)] } \\
{[\mathbf{m m}]}\end{array}$ & $\begin{array}{c}l \text { [Equation (4)] } \\
{[\mathbf{m m}]}\end{array}$ \\
\hline Carbon & 0.12 & 0.54 & 0.36 & 0.04 & 0.102 & 176 & 70 \\
FRCM & 0.30 & 0.80 & 0.98 & 0.07 & 0.416 & 203 & 86 \\
\hline
\end{tabular}

The CMLs are depicted in Figure 14, where the non-linear CML measured on FRCMconcrete joints with the same PBO textile using strain gauges attached to the fibers in [21] is also provided for comparison.

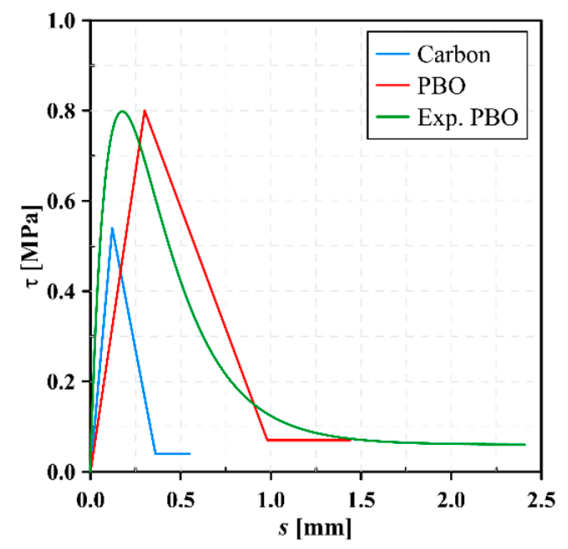

Figure 14. Comparison between the CMLs calibrated for carbon and PBO FRCM and the non-linear CML measured on PBO FRCM-concrete joints by [21].

Figure 14 shows that the CML calibrated for the PBO FRCM and that measured on PBO FRCM-concrete joints [21] with the same textile are similar, although the matrix employed in this study and that in [21] were different. The matrix employed for the FRCM strips 
in [21] was specifically design to be applied on concrete substrates and had an average compressive strength $f_{c}=28.4 \mathrm{MPa}$, whereas that employed in this paper was designed for masonry substrates and had $f_{c}=25 \mathrm{MPa}$ (Table 1). The limited differences in the PBO CMLs depicted in Figure 14 indicate that the calibration strategy adopted was effective in catching the main features of the matrix-fiber CML and that the matrix strength did not play a fundamental role in the definition of the CML.

The carbon CML showed a maximum shear stress and corresponding slip significantly lower than those of PBO CML (Figure 14). Moreover, the debonding of carbon fibers occurred at a slip $s_{f}=0.36 \mathrm{~mm}$, which is smaller than that associated with PBO fiber debonding ( $s_{f}=0.98 \mathrm{~mm}$ ). Therefore, the fracture energy $G_{F}$ of the carbon CML is approximately $25 \%$ of that of the PBO CML, which entails for a debonding stress $\sigma_{d e b}$ of the carbon FRCM equal to $50 \%$ of that of a corresponding PBO FRCM with the same geometrical properties [38].

The effective bond length $l_{\text {eff }}$ and the length of portion associated with softening $l$ for the carbon and PBO FRCM were computed with Equations (3) and (4), respectively, assuming $\alpha=0.99$ [39]. The results obtained, provided in Table 4 , show that although the CML were significantly different, the effective bond lengths obtained for carbon $\left(l_{\text {eff }}=176 \mathrm{~mm}\right)$ and PBO $\left(l_{\text {eff }}=206 \mathrm{~mm}\right.$ ) FRCM have a difference of approximately 15\% (a similar consideration can be made regarding the softening length $l$ ). However, previous results showed that the determination of the effective bond length of FRCM composites considering results from a single bonded length may provide misleading results [39]. Therefore, further studies are needed to confirm the values of $l_{\text {eff }}$ found in this work.

\subsection{Simulation of the Load Response}

Once the CML is known, the load response can be constructed according to the equations in Table 3. The load responses obtained using the calibrated CMLs are depicted in Figure 15, where the envelope of the experimental load responses (see Figures 5 and 7) are also reported for comparison. Despite the experimental results showed a significant scatter, as often observed in the literature $[6,21,24]$, the analytical load responses matched well the experimental envelope curves up to the peak load. The analytical post-peak behavior was characterized by the presence of snap-back, whereas the global slip continued to increase during the experimental softening stage. This difference is caused by the experimental test control mode, which enforced a monotonical increase of global slip during the entire tests. Further details regarding the occurrence of snap-back in analytical and experimental FRP-substrate and FRCM-substrate joints can be found in [41,47].

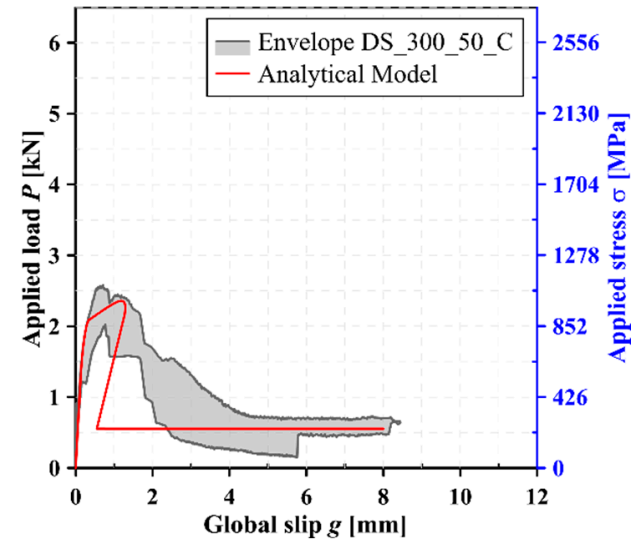

(a)

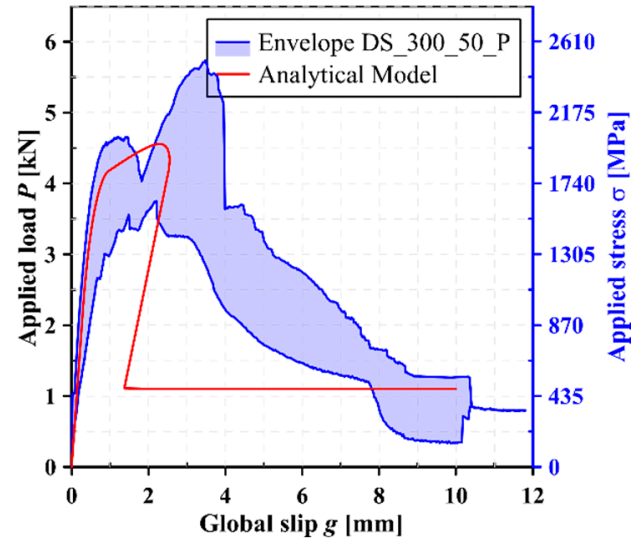

(b)

Figure 15. Comparison of analytical and experimental (envelope) load responses for (a) carbon and (b) PBO FRCM. 


\section{Conclusions}

The bond behavior of three types of FRCM composites and one SRG composite applied onto a masonry substrate was investigated in this paper. The FRCM composites comprised a carbon, $\mathrm{PBO}$, or AR-glass textile and two types of cement-based matrices, whereas the SRG composite comprised a unidirectional stainless-steel cord textile embedded within a lime-based matrix. Sixteen single-lap direct shear tests, four for each composite type, were carried out.

The results showed different failure modes, even for the same composite. Debonding at the matrix-fiber interface occurred in all composites, although it was associated with other failure modes sometimes, such as debonding at the matrix-substrate interface (observed in carbon FRCM and SRG) and fiber rupture (observed in AR-glass FRCM and $\mathrm{SRG}$ ). Depending on the composite, matrix transversal and longitudinal cracks were also observed, which were responsible for matrix-substrate failure and interlaminar matrix failure, respectively.

The applied load-global slip responses observed always showed an initial linear branch followed by a non-linear behavior up to the peak load. The carbon and PBO FRCM composites showed the presence of friction among the fiber filaments and between fibers and matrix, which was responsible for an increase of the applied load after the onset of debonding. For the AR-glass FRCM, it was not possible to clearly recognize the contribution of friction due to the occurrence of fiber subsequent rupture. Depending on the failure mode, specimens showed a load response softening branch (see e.g., carbon and PBO FRCM) or sudden decreases of the applied load due to fiber rupture (see e.g., AR-glass FRCM) or debonding at the matrix-substrate interface (see e.g., SRG composite).

The results obtained for carbon and PBO FRCM were modeled using an analytical approach based on the solution of the bond differential equation using a trilinear cohesive material law. The analytical and experimental load responses agreed well up to the peak load, whereas differences were observed in the descending branch due to the presence of a snap-back in the analytical response.

Author Contributions: Conceptualization, K.A.-L., and T.D.; experimental program, T.D. and K.A.-L.; analytical study, T.D., and P.C.; investigation, K.A.-L. and T.D.; writing-original draft, K.A.-L.; writing — draft review, T.D.; writing — editing T.D. and P.C. All authors have read and agreed to the published version of the manuscript.

Funding: This research received no external funding.

Data Availability Statement: The data presented in this study are available on request from the corresponding author. The data are not publicly available because part of an ongoing research.

Acknowledgments: This research was performed with the support of the Laboratorio Prove Materiali of the Politecnico di Milano.

Conflicts of Interest: The authors declare no conflict of interest.

\section{References}

1. Abid, S.R.; Al-lami, K. Critical review of strength and durability of concrete beams externally bonded with FRP. Cogent Eng. 2018, 5. [CrossRef]

2. Al-Lami, K.; Colombi, P.; D'Antino, T. Influence of hygrothermal ageing on the mechanical properties of CFRP-concrete joints and of their components. Compos. Struct. 2020, 238, 111947. [CrossRef]

3. Heshmati, M.; Haghani, R.; Al-Emrani, M. Environmental durability of adhesively bonded FRP/steel joints in civil engineering applications: State of the art. Compos. Part B Eng. 2015, 81, 259-275. [CrossRef]

4. Maljaee, H.; Ghiassi, B.; Lourenço, P.B.; Oliveira, D.V. FRP-brick masonry bond degradation under hygrothermal conditions. Compos. Struct. 2016, 147, 143-154. [CrossRef]

5. Bencardino, F.; Condello, A.; Ashour, A.F. Single-lap shear bond tests on Steel Reinforced Geopolymeric Matrix-concrete joints. Compos. Part B Eng. 2017, 110, 62-71. [CrossRef]

6. Franzoni, E.; Gentilini, C.; Santandrea, M.; Carloni, C. Effects of rising damp and salt crystallization cycles in FRCM-masonry interfacial debonding: Towards an accelerated laboratory test method. Constr. Build. Mater. 2018, 175, 225-238. [CrossRef] 
7. Carozzi, F.G.; Bellini, A.; D'Antino, T.; de Felice, G.; Focacci, F.; Hojdys, Ł.; Laghi, L.; Lanoye, E.; Micelli, F.; Panizza, M.; et al. Experimental investigation of tensile and bond properties of Carbon-FRCM composites for strengthening masonry elements. Compos. Part B Eng. 2017, 128, 100-119. [CrossRef]

8. Koutas, L.N.; Tetta, Z.; Bournas, D.A.; Triantafillou, T.C. Strengthening of Concrete Structures with Textile Reinforced Mortars: State-of-the-Art Review. J. Compos. Constr. 2019, 23, 1-20. [CrossRef]

9. ACI. 549.4R-20 Guide to Design and Construction of Externally Bonded Fabric-Reinforced Cementitious Matrix and Steel-Reinforced Grout Systems for Repair and Strengthening of Concrete Structures; American Concrete Institute: Farmington Hills, MI, USA, 2013.

10. CNR. CNR-DT 215/2018 Guide for the Design and Construction of Externally Bonded FRP Systems for Strengthening Existing Structures; National Research Council: Rome, Italy, 2018. Available online: https:/ /www.cnr.it/en/node/12827 (accessed on 7 January 2021).

11. CSLLPP. Linea Guida per la Identificazione, la Qualificazione ed il Controllo di Accettazione di Compositi Fibrorinforzati a Matrice Inorganica (FRCM) da Utilizzarsi per il Consolidamento Strutturale di Costruzioni Esistenti; Consiglio Superiore dei Lavori Pubblici: Rome, Italy, 2018. Available online: https://www.ruregold.com/wp-content/uploads/2019/01/linee-guida-frcm-2018.pdf (accessed on 7 January 2021). (In Italian)

12. Ombres, L.; Verre, S. Flexural Strengthening of RC Beams with Steel-Reinforced Grout: Experimental and Numerical Investigation. J. Compos. Constr. 2019, 23, 04019035. [CrossRef]

13. De Santis, S. Bond behaviour of Steel Reinforced Grout for the extrados strengthening of masonry vaults. Constr. Build. Mater. 2017, 150, 367-382. [CrossRef]

14. Marcari, G.; Basili, M.; Vestroni, F. Experimental investigation of tuff masonry panels reinforced with surface bonded basalt textile-reinforced mortar. Compos. Part B Eng. 2017, 108, 131-142. [CrossRef]

15. Caggegi, C.; Carozzi, F.G.; De Santis, S.; Fabbrocino, F.; Focacci, F.; Hojdys, Ł.; Lanoye, E.; Zuccarino, L. Experimental analysis on tensile and bond properties of $\mathrm{PBO}$ and aramid fabric reinforced cementitious matrix for strengthening masonry structures. Compos. Part B Eng. 2017, 127, 175-195. [CrossRef]

16. D'Ambrisi, A.; Focacci, F.; Luciano, R.; Alecci, V.; De Stefano, M. Carbon-FRCM materials for structural upgrade of masonry arch road bridges. Compos. Part B Eng. 2015, 75, 355-366. [CrossRef]

17. Arboleda, D. Fabric Reinforced Cementitious Matrix (FRCM) Composites for Infrastructure Strengthening and Rehabilitation: Characterization Methods. Ph.D. Thesis, University of Miami, Coral Gables, FL, USA, 2014; pp. 1-131.

18. D'Antino, T.; Carozzi, F.G.; Colombi, P.; Poggi, C. Out-of-plane maximum resisting bending moment of masonry walls strengthened with FRCM composites. Compos. Struct. 2018, 202, 881-896. [CrossRef]

19. Nobili, A. Durability assessment of impregnated Glass Fabric Reinforced Cementitious Matrix (GFRCM) composites in the alkaline and saline environments. Constr. Build. Mater. 2016, 105, 465-471. [CrossRef]

20. Williams Portal, N.; Flansbjer, M.; Johannesson, P.; Malaga, K.; Lundgren, K. Tensile behaviour of textile reinforcement under accelerated ageing conditions. J. Build. Eng. 2016, 5, 57-66. [CrossRef]

21. D'Antino, T.; Carloni, C.; Sneed, L.H.; Pellegrino, C. Matrix-fiber bond behavior in PBO FRCM composites: A fracture mechanics approach. Eng. Fract. Mech. 2014, 117, 94-111. [CrossRef]

22. de Felice, G.; D’Antino, T.; De Santis, S.; Meriggi, P.; Roscini, F. Lessons Learned on the Tensile and Bond Behavior of Fabric Reinforced Cementitious Matrix (FRCM) Composites. Front. Built Environ. 2020, 6, 1-15. [CrossRef]

23. Borri, A.; Castori, G.; Corradi, M. Shear behavior of masonry panels strengthened by high strength steel cords. Constr. Build. Mater. 2011, 25, 494-503. [CrossRef]

24. Sneed, L.H.; D'Antino, T.; Carloni, C. Investigation of bond behavior of polyparaphenylene benzobisoxazole fiber-reinforced cementitious matrix composite-concrete interface. ACI Mater. J. 2014, 111, 569-580. [CrossRef]

25. Calabrese, A.S.; D'Antino, T.; Colombi, P.; Poggi, C. Study of the influence of interface normal stresses on the bond behavior of FRCM composites using direct shear and modified beam tests. Constr. Build. Mater. 2020, 262, 120029. [CrossRef]

26. Terreal Italia San Marco Vivo Red Bricks. Tech. Doc. Available online: https://www.sanmarco.it/scheda-prodotto.php?idcategoria $=2 \&$ id-prodotto $=36$ (accessed on 3 November 2020).

27. D'Antino, T.; Santandrea, M.; Carloni, C. Advances in Knowledge of the Fracture Properties of Cohesive Materials: Fired-Clay and Tuff Bricks. J. Eng. Mech. 2020, 146, 4020079. [CrossRef]

28. FASSA BORTOLO MS 20, Malta cementizia fibrorinforzata per muratura ed intonaco, per interni ed esterni. Tech. Doc. 2019, 2-3. Available online: https://www.fassabortolo.it/it/prodotti/-/p/6/56/prodotti-tradizionali/ms-20-malta-cementizia-permuratura-ed-intonaco-da-utilizzare-a-mano-per-interni-ed-esterni (accessed on 3 November 2020).

29. Ruregold PBO-Mesh Gold 70/18 \& PBO-MX GOLD MURATURA. Tech. Doc. 2019. Available online: https://www.ruregold.com/ (accessed on 3 November 2020).

30. TCS B-STRUCTURA. Tech. Doc. 2020. Available online: https://www.tcscalce.it/en/prodotto/b-structura (accessed on 3 November 2020).

31. Hausding, J.; Lorenz, E.; Ortlepp, R.; Lundahl, A.; Cherif, C. Application of stitch-bonded multi-plies made by using the extended warp knitting process: Reinforcements with symmetrical layer arrangement for concrete. J. Text. Inst. 2011, 102, 726-738. [CrossRef]

32. Mazzucco, G.; D'Antino, T.; Pellegrino, C.; Salomoni, V. Three-dimensional finite element modeling of inorganic-matrix composite materials using a mesoscale approach. Compos. Part B Eng. 2018, 143, 75-85. [CrossRef] 
33. TCS Steel X800-A4. Tech. Doc. 2020, 1-3. Available online: https://www.tcscalce.it/en/prodotto/tcs-steel-x800-a4 (accessed on 3 November 2020).

34. D'Ambrisi, A.; Feo, L.; Focacci, F. Experimental analysis on bond between PBO-FRCM strengthening materials and concrete. Compos. Part B Eng. 2013, 44, 524-532. [CrossRef]

35. Askouni, P.D.; Papanicolaou, C.G. Experimental investigation of bond between glass textile reinforced mortar overlays and masonry: The effect of bond length. Mater. Struct. Constr. 2017, 50, 1-15. [CrossRef]

36. Santandrea, M.; Focacci, F.; Mazzotti, C.; Ubertini, F.; Carloni, C. Determination of the interfacial cohesive material law for SRG composites bonded to a masonry substrate. Eng. Fail. Anal. 2020, 111, 104322. [CrossRef]

37. Sika Sika MonoTop ${ }^{\circledR}-722$ Mur. Tech. Doc. 2019, 1-4. Available online: https://ita.sika.com/it/edilizia/rinforzi-eincollaggistrutturali/sistemi-antisfondellamentopersolai/sika-monotop-722mur.html (accessed on 3 November 2020).

38. Carloni, C.; D'Antino, T.; Sneed, L.H.; Pellegrino, C. Role of the matrix layers in the stress-transfer mechanism of FRCM composites bonded to a concrete substrate. J. Eng. Mech. 2015, 141, 1-10. [CrossRef]

39. D'Antino, T.; Colombi, P.; Carloni, C.; Sneed, L.H. Estimation of a matrix-fiber interface cohesive material law in FRCM-concrete joints. Compos. Struct. 2018, 193, 103-112. [CrossRef]

40. Colombi, P.; D'Antino, T. Analytical assessment of the stress-transfer mechanism in FRCM composites. Compos. Struct. 2019, 220, 961-970. [CrossRef]

41. Calabrese, A.S.; Colombi, P.; D'Antino, T. Analytical solution of the bond behavior of FRCM composites using a rigid-softening cohesive material law. Compos. Part B Eng. 2019, 174, 107051. [CrossRef]

42. Wu, Z.; Yuan, H.; Niu, H.; Zhishen, W.; Hong, Y.; Hedong, N. Stress transfer and fracture propagation in different kinds of adhesive joints. J. Eng. Mech. 2002, 128, 562-573. [CrossRef]

43. Dai, J.; Ueda, T.; Sato, Y. Development of the Nonlinear Bond Stress-Slip Model of Fiber Reinforced Plastics Sheet-Concrete Interfaces with a Simple Method. J. Compos. Constr. 2005, 9, 52-62. [CrossRef]

44. Focacci, F.; Carloni, C. Periodic variation of the transferable load at the FRP-masonry interface. Compos. Struct. 2015, 129, 90-100. [CrossRef]

45. Yuan, H.; Teng, J.G.; Seracino, R.; Wu, Z.S.; Yao, J. Full-range behavior of FRP-to-concrete bonded joints. Eng. Struct. 2004, 26, 553-565. [CrossRef]

46. Dai, J.; Ueda, T.; Sato, Y. Unified analytical approaches for determining shear bond characteristics of FRP-concrete interfaces through pullout tests. J. Adv. Concr. Technol. 2006, 4, 133-145. [CrossRef]

47. Carrara, P.; Ferretti, D. A finite-difference model with mixed interface laws for shear tests of FRP plates bonded to concrete. Compos. Part B Eng. 2013, 54, 329-342. [CrossRef] 